Portland State University

PDXScholar

$11-18-1985$

\title{
A Comparative Study of the Northwestern Syntax Screening Test Data
}

Sharon Ann Moore

Portland State University

Follow this and additional works at: https://pdxscholar.library.pdx.edu/open_access_etds

Part of the Speech Pathology and Audiology Commons, and the Syntax Commons Let us know how access to this document benefits you.

\section{Recommended Citation}

Moore, Sharon Ann, "A Comparative Study of the Northwestern Syntax Screening Test Data" (1985). Dissertations and Theses. Paper 3535.

https://doi.org/10.15760/etd.5418

This Thesis is brought to you for free and open access. It has been accepted for inclusion in Dissertations and Theses by an authorized administrator of PDXScholar. Please contact us if we can make this document more accessible: pdxscholar@pdx.edu. 
AN ABSTRACT OF THE THESIS OF Sharon Ann Moore for the Master of Science in Speech Communication, with an emphasis in Speech-Language Pathology, presented November 18, 1985.

Title: A Comparative Study of the Northwestern Syntax Screening Test Data.

APPROVED BY MEMBERS OF THE THESIS COMMITTEE:

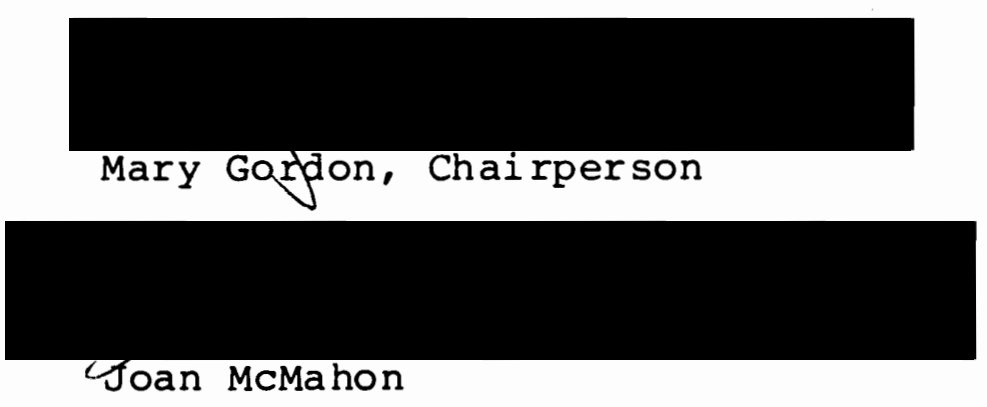

Numerous tests have been developed to assess the language abilities of children. In an attempt to develop an efficient tool for screening the morphological and syntactical language skills of children, Lee $(1969,1971)$ and her students produced the Northwestern Syntax Screening Test (NSST) .

The purpose of this study was to compare NSST data (Lee, 1969, 1971) with data obtained in Portland, Oregon for children 4.0-4.11 years of age. The questions this study sought to answer were: 1) Is there a significant difference between the expressive and receptive scores obtained by Lee, (1969, 1971) and the scores obtained in Portland, Oregon? 
2) What are the means, standard deviations and percentiles of the NSST scores of a select group of four-year-old children in Portland, Oregon?

Twenty-two children, 4.0-4.5 years of age, and twentytwo children, 4.6-4.11 years of age, were selected as subjects. They met the following criteria: normal hearing, no apparent speech or language deficiencies (past or present), speaks standard English, from middle socioeconomic level home and parent permission received.

The mean score on the receptive portion of the NSST for the children tested in this study was 27.95 with a standard deviation of 4.28 . The Lee $(1969,1971)$ data revealed a mean score of 27 with a standard deviation of 5.69 . The Lee (1969, 1971) study resulted in an expressive mean score of 25 with a standard deviation of 5.39. When a two-tailed $\underline{t}$-test was used, the results showed no statistically significant difference between the data of the two studies.

This study revealed information to support: 1) the use of the NSST norms for the Portland, Oregon four-year-old group; and 2) findings that the receptive language processing skills develop before the expressive language skills. In addition, the frequency of errors on certain items revealed item weakness. 


\title{
A COMPARATIVE STUDY OF THE NORTHWESTERN SYNTAX SCREENING TEST DATA
}

by

SHARON ANN MOORE

\begin{abstract}
A thesis submitted in partial fulfillment of the requirements for the degree of
\end{abstract}
MASTER OF SCIENCE IN SPEECH COMMUNICATION: with an emphasis in SPEECH-LANGUAGE PATHOLOGY/AUDIOLOGY

Portland State University

1985 
TO THE OFFICE OF GRADUATE STUDIES AND RESEARCH:

The members of the Committee approve the thesis of Sharon Ann Moore presented November 18, 1985.

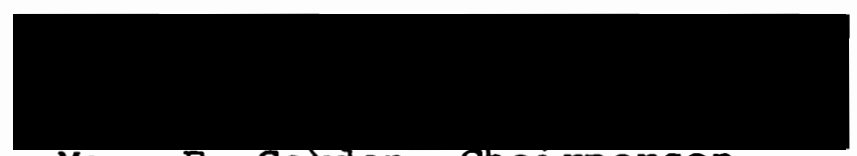

Mary E. Goraon, chalrperson

Joan McMahon

APPROVED :

Theodore G. Grove, Chair, Department of Speech Communication

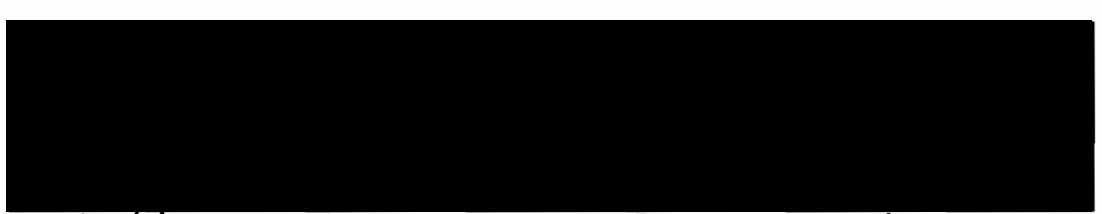

Jim/ Feath, Dean, Graduate Studies

and Research 


\section{ACKNOWL EDGEMENTS}

Upon completion of this thesis, I look back and remember those who have helped make this day possible. Thank you all for your help.

A special thank you to: the children and their parents and guardians for participating in the study; my friends from the study group for always being there when I needed them; Dr. Casteel for counseling when I returned to school and encouragement through periods of uncertainty; Mary Gordon for support and advice throughout my coursework and this project; and Joan McMahon for participating on the committee. You have been true friends.

I am very grateful for all of your support. 
TABLE OF CONTENTS

PAGE

AC KNOWLEDGEMENTS

LIST OF TABLES

vi

LIST OF FIGURES

vii

CHAPTER

I INTRODUCTION AND STATEMENT OF PURPOSE . •

Int roduction

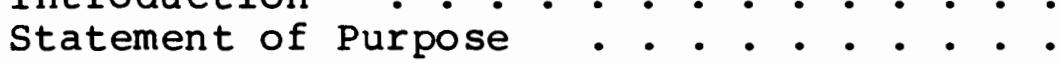

II REVIEW OF THE LITERATURE

Introduction

Structure of Language . . . . . . . . .

Development of Language Assessment Tools. Subjective Evaluation ... . . . .

Morphological Assessment . . . . .

Morphological and Word Order Assessment

Northwestern Syntax Screening Test (NSST).

Description .............

Subjects

Interpretation and Results .....

Criticisms of the NSST .......

Application Beyond Intended Purposes. Lack of Representative Norms . . . Questionable Developmental Accuracy Lack of Relationship Between the NSST

Scores and Spontaneous Speech

Summary

Lack of Reliability and Validity Data 
PAGE

Scoring Procedures . . . . . . . 23

Data Analysis . . . . . . . 24

IV RESULTS AND DISCUSSION $\quad$ • • • • • • • . 24

Results •. . . . . . . . . . 24

Discussion . . . . . . . . . . . 26

V SUMMARY AND IMPLICATIONS • • • • . • . 36

Summary • . • • • . • • • • • 36

Implications • • • • . . • • • . 37

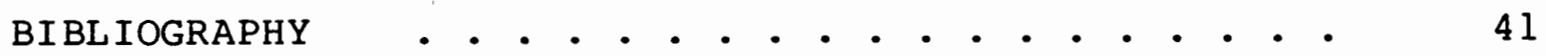

APPENDICES $\quad$ • . . . . . . . . . . . . . . . . . 45 


\section{LIST OF TABLES}

TABLE

PAGE

I Comparison of NSST Means and Standard Deviations Obtained in the Midwest and Portland, Oregon . . . . . . .

I Comparison of Number of Correct Items Per Subject in Each Percentile Rank Using Midwest Norms and Portland, Oregon Norms

III Item Analysis Frequency of Errors Per Test Item 


\section{LIST OF FIGURES}

FIGURE

PAGE

I Scattergram of Score Distribution on

Receptive Section of NSST ..... . 31

II Scattergram of Score Distribution on

Expressive Section of NSST . . . . 32 


\section{CHAPTER I}

\section{INTRODUCTION AND STATEMENT OF PURPOSE}

\section{Introduction}

During recent years, many speech-language pathologists have focused their attention upon language development and usage. One of the early studies in this area involved imitation, comprehension and production (Fraser, Bel lugi and Brown, 1963). Interest in the reported findings led Northwestern University students, under the direction of Laura Lee, to pursue independent language studies. From the data gathered, the Northwestern Syntax Screening Test (NSST) was devised (Lee, 1969, 1971).

The NSST was developed as a "diagnostic indicator," rather than as a diagnostic test, in response to a need for a time-efficient screening device to help identify children who need further assessment to determine whether a language deficit exists (Lee, 1977). This tool was developed for use in four situations: 1) when large numbers of children need to be screened; 2) when it is difficult to obtain a representative sample of a child's spontaneous speech; 3 ) when the receptive abilities of a physically handicapped child who cannot produce intelligible speech need to be evaluated; or 4) when the grammatical structure of a child who has voice, 
stuttering, or articulation as their main problem needs to be assessed (Lee, 1977). It was designed to provide a means of comparing an individual child's estimated receptive and expressive abilities without using the more complicated language sampling procedures. Bannatyne (1975) suggested the NSST be used as a pre-and post-test of acquisition of syntax. Since its development, it has been widely used by speechlanguage pathologists (Lee, 1977).

The NSST was originally utilized with children 3.0 through 7.11 years of age. The normed scores for the ages 7.0-7.11 years were found to be less accurate, so application of the NSST beyond the 6.11 year level has not been recommended (Arndt, 1977; Lee, 1977). In addition, this instrument is limited to use with children learning and speaking standard English (Callahan, 1974; Lee, 1977).

Numerous criticisms have been made of the NSST. Lack of statistical data regarding its reliability and validity is evident (Arndt, 1977; Lee, 1977; Logue, 1978; McCauley and Swisher, 1984). The use of the delayed imitation technique has been questioned (Prutting, Gallagher and Mulac, 1975). Some people state the NSST data are based upon a sample that was not representative of the general population (Arndt, 1977; Larson and Summers, 1976). Frequently the NSST results have been used beyond their intended screening function (Logue, 1978).

In a written reply, Lee (1977) has addressed many of the critical comments. Among other factors, she has 
acknowledged that the NSST normative data were based upon children from middle and upper-middle socioeconomic groups, and this factor should be considered by the examiner. She has recommended that anyone using the NSST should use normative data established for their particular geographic and and socio-economic population, rather than relying upon the data she and her associates collected.

\section{Statement of Purpose}

The purpose of this study was to compare Lee's NSST data (Lee, 1969, 1971) with data obtained in Portland, Oregon, for children 4.0-4.11 years of age.

This investigation sought to answer the following questions :

1. Is there a significant difference between the expressive and receptive scores obtained by Lee (1969, 1971) and the scores obtained in Portland, Oregon?

2. What are the means, standard deviations and percentiles of the NSST scores of a select group of four-year old children in Portland, Oregon? 
CHAPTER I I

REVIEW OF THE LITERATURE

\section{Introduction}

One of the responsibilities of the speech-language pathologists is to identify children who have language deficiencies. Because language assessment can be a timeconsuming task, much research has been conducted in an attempt to find an accurate and time-efficient method to locate children who may have language deficiencies. This review of the literature briefly describes the structure of language and outlines the development of language assessment tools. The NSST and its procedures are explained. Following a review of previous NSST research, the application and limitations of the NSST are presented. Finally, this researcher presents support for further normative data research in other geographic locations where the NSST is utilized.

\section{Structure of Language}

Various methods have been devised to categorize language (Brown, 1973; Chomsky, 1965; Nation and Aram, 1977; Peterson and Marquardt, 1981; Wiig and Semel, 1980; and Wood, 1981). A common classification system considers four levels of language, including: 1) phonology which is concerned with 
the description of sounds in a language and the rules governing the sound sequences; 2) syntax which is centered upon word order and morphology or word formation; 3) semantics which is focused upon meaning; and 4) pragmatics which is concerned with understanding and using the rules of functional language usage (Nation and Araam, 1977).

This study focuses upon the construct of syntax, i.e., word order and word formation. Rules governing words as they relate to one another involve the use of words, phrases and clauses in sentence formation. Through the use of phrase structure rules, one- or two-word noun and verb utterances can be expanded and described. By using the rules of transformation, which can add, delete, substitute or reorder the phrase structure of a sentence, the surface form of the sentence is developed (Wiig and semel, 1980). The syntactic development of language in children follows a developmental sequence generally beginning with one-word utterances, progressing to two-word utterances, then phrases and finally simple to complex sentences. Between the ages of two and three and one-half years, a child usually develops the phrase structure rules and early transformational structures. By the age of four to five years, a child has acquired most of the syntactic forms commonly used in adult speech (Nation and Aram, 1977).

Morphology is centered upon the patterns of word formation in a language. Words are composed of morphemes which Wiig and Semel (1980) define as "the smallest unit of 
meaning." Features which indicate plurality and possession of nouns, comparison for adjectives and adverbs, tense of verbs and addition of suffixes and prefixes to root words are included under the term morphology.

With an understanding of the basic terminology of language, the reader will be able to follow the development of assessment tools, particularly the NSST. The NSST items assess word order and morphology.

\section{Development of Language Assessment Tools}

Subjective Evaluation

Prior to the development of formal language tests, speech-language pathologists judged a child's receptive syntactic language through activities requiring him to follow directions or to identify pictures (Lee, 1970). To assess a child's expressive syntactic language, he was engaged in general conversation through the use of questions or pictures. From a child's responses, the speech-language pathologist subjectively evaluated a child's language as normal or deficient in the use of grammatical rules. Evaluation of specific syntactical attributes such as nouns, verb tense and word order was helpful, but was not very thorough or consistent. A more standardized approach using developmental scales or normative data was needed to make more accurate and objective assessments. 
Morphological Assessment

One of the first tests for evaluating expressive morphological abilities, the Berko Test of Morphology, was developed by Berko (1958). This test presents sentence completion tasks requiring the child to use appropriate morphological endings with nonsense words. The Grammatic Closusre Subtest of the Illinois Test of Psycholinguistic Abilities (Kirk, McCarthy and Kirk, 1968) employs similar sentence completion activities with meaningful words to assess a child's usage of morphological structures. These tools, however, do not evaluate other syntactical constructs of language, e.g., questions, noun phrases, passives, negatives and auxillary verbs.

Morphological and Word order Assessment

Because Lerea (1958a) found picture vocabulary and language structure inventories to be sensitive to identifying children with language deficiencies, he developed the Michigan Picture Language Inventory (Lerea, 1958b) in which a comparison is made between receptive and expressive abilities of vocabulary and structure at similar levels of difficulty. For the expressive items, he used sentence completion tasks similar to Berko (1958) and Kirk et al. (1968) requiring oneword responses. For the receptive portion, the child is required to point to the word spoken by the examiner.

In an attempt to assess language structures such as 
morphology, grammar and syntax, Carrow (1968a) investigated the development of auditory comprehension in children. She developed a receptive test, the Test of Auditory Comprehension of Language (Carrow, 1968b), which requires the child to point to the picture that illustrates the clinician's stimulus word or sentence.

Fraser et al. (1963) developed the Imitation, Comprehension and Production Test (ICP) which was the forerunner of the NSST. It was based upon comparing comprehension or understanding (C) with production through the use of speech (P) and with production following a model or imitation (I). For each comprehension item, a contrasting pair of sentences was presented, and the subject was instructed to point to the picture which best matched the examiner's sentence. The imitation task required the child to repeat a sentence after the examiner. In the production task, the examiner presented two pictures and said two sentences being careful not to match the sentence to the appropriate picture. Then he pointed to each picture and instructed the subject to identify them. This test involved ten different grammatical contrasts with each being tested in the three ways described above, i.e., imitation, comprehension and production. The areas tested were subject-distinction, noun phrase and prepositional phrase recognition and direct and indirect object placement (Fraser et al., 1963).

From the ICP testing, the examiner is able to compare a child's ability to imitate, comprehend and produce similar 
grammatical forms (Lee, 1970). According to Fraser et al. (1963), the results of this study with three-year old children showed the general progression from imitation to comprehension to production in the development of language in children.

The information from the Fraser et al. (1963) study interested graduate students at Northwestern University under the direction of Lee. Based upon the basic features of the ICP, they created a measurement tool to be used for screening purposes. Their purpose was to develop an instrument to identify those children with language deficiencies who needed further language study and analysis. From 1967-1969, they gathered normative data using the NSST (Lee, 1969, 1971).

\section{Northwestern Syntax Screening Test (NSST)}

Description

In an attempt to expedite the task of identifying children who have language inadequacies, Lee's students developed the NSST using the sentence contrast format of the ICP. The NSST contains both receptive and expressive portions, each presenting similar syntactic forms. The receptive portion contains twenty pages displaying four pictures on each page. The child is instructed to listen as the examiner states two sentences involving two of the pictures. The other two pictures on each page are decoys. The child is then instructed to point to the picture that best matches the sentence spoken 
by the examiner. After the child responds, the second sentence is presented. A total of forty sentences are presented.

The expressive portion presents similar structures using different pictures. Two pictures are shown on each page. The examiner instructs the child to listen as he states two sentences describing the pictures. The child is then instructed to repeat verbatim the sentence spoken by the examiner that describes the picture to which the examiner is pointing. The second sentence is tested in the same manner. A total of forty sentences are presented.

The NSST does not include the immediate (rote) imitation task which was included in the ICP. Instead, Lee and her students utilized a delayed imitation task which is coupled with a picture identification task. According to Dailey and Boxx (1979), sentences to be imitated in assessing syntactic abilities must exceed the child's short-term memory. The delayed imitation task should off-set the shorter sentence length of some of the items, and therefore meet the criterion of exceeding the child's short-term memory.

The entire test (eighty sentences) is given to each child and requires fifteen to twenty minutes to administer. The grammatical structures tested by the receptive and expressive sections include, in order of increasing difficulty, prepositions, personal pronouns, plurals, negatives, verb tenses, reflexive pronouns, possessives, wh-questions, yes-no questions, and passive and indirect objects (Lee, 1970) 
$\underline{\text { Subjects }}$

The 344 subjects, 164 males and 180 females between the ages of 3.0-7.11 years, used in the developmental studies were from nursery schools and kindergartens in the area surrounding Northwestern University in Evanston, Illinois, which was a middle to middle-upper socioeconomic level suburban community. There was no difference in the test results between the male and female scores, so the data were collapsed into age groups with no sex distinctions (Lee, 1969, 1971). The criteria for inclusion as subjects were: 1) the children were judged by their teachers to be free from handicapping conditions which would hinder normal language development and 2) standard English was spoken in the home (Lee, 1969, 1971).

\section{Interpretation and Results}

The tests were scored and the results were plotted on two charts so that a child's scores can be compared to these receptive and expressive normative scores. Each chart shows the $90 \mathrm{th}, 75 \mathrm{th}, 50 \mathrm{th}, 25 \mathrm{th}$ and $10 \mathrm{th}$ percentiles for each age group. When the child's scores place him between the 10th percentile and the second standard deviation or lower, further in-depth assessment is indicated to determine whether a language deficiency does exist and to find areas of language weakness and strengths. In interpreting a particular child's scores, the examiner should be aware of the child's age in 
months as well as years. For example, has the child just become four years old or is he almost five years old? Basic guidelines for interpretation of the test results are included in the manual (Lee, 1969, 1971).

Usually the test results will reveal higher receptive scores than expressive scores. For subjects who have receptive and/or expressive scores which are more than two standard deviations below the mean, the child will generally need language intervention. When the child's scores place him between the loth percentile and the second standard deviation, he is considered as low-normal in language development, and further assessment is recommended. If the child's expressive score is higher than his receptive score, several factors may play a part. The receptive section was probably administered first, and the child became familiar with the task by the time the expressive portion was presented. If the receptive score is very low and the expressive score is established in the normal range, the child may be completing the expressive task with repetition without comprehension. This type of response may be an indication of some type of emotional problem or brain damage. To follow the intended purpose of the NSST, children who are found to have scores which indicate possible language deficiencies should receive an in-depth evaluation (Lee, 1969, 1971, 1977).

\section{Criticisms of the NSST}

Application Beyond Intended Purposes. The NSST has 
been widely used (Lee, 1977), and Logue (1978) has noted frequent misuse and misinterpretation of the NSST beyond its intended syntactic screening purpose. It has even been used as a basis for planning remedial intervention. Lee (1977) has frequently cautioned against overextending the use of the NSST scores. The NSST does not compute a language age for a child. It was not meant to be a tool for assessing all aspects of a child's language development. Instead it was developed as a screening tool to be used by speech-language pathologists to obtain an estimate of a child's syntactic and morphological abilities.

Lack of Representative Norms. Application of the NSST norms to other populations has been limited. The NSST was based upon the performances of white children from Midwest middle to middle-upper socioeconomic level families who spoke standard English. Obviously, this is not a representative sample of the general population (Arndt, 1977; Fontana, 1978; Larson and Summers, 1976).

An attempt was made by Toronto to develop a language screening test for the Spanish population. Using the NSST format and methods, he devised the screening Test of Spanish Grammar (STSG) (Toronto, 1973). Because of the differences in vocabulary and syntax acquisition patterns between English and Spanish speaking individuals, he attempted to provide something more than a translation of the NSST. In reviews of the STSG, however, it appears the STSG tests "Spanish equivalents of English syntax" and was normed on a 
language development. As a partial solution to this problem, Pressnell (1973) combined the NSST and the Developmental Sentence Score (DSS) to compare the language abilities of hearing-impaired children. She found that these assessment tools which were based upon a hearing population revealed the hearing-impaired children most frequently used verbs incorrectly and had a different sequential acquisition of verbs.

Martin and Engel (1978) used the NSST as a language assessment tool with thirty trainable mentally retarded subjects. They found this population gave more correct responses when concrete objects, rather than pictures, were used. On the receptive portion, 50 per cent of the subjects tested made errors on the NSST, but not on the concrete object version of the NSST. The variables of auditory memory span, perceptual cue organization, attention span and difficulty in transference of learning were probable reasons for the test results.

The socioeconomic level and geographic locality of the child being tested were found by Larson and Summers (1976) to have a significant effect on the comparison of their NSST study results with the Lee $(1969,1971)$ normative data. The mean scores of their subjects from lower socioeconomic backgrounds in Texas were significantly lower than the NSST norms .

Questionable Developmental Accuracy. Lee (1969, 1971), Arndt (1977) and Larson and Summers (1976) have noted that the test is insensistive to the grammatical language 
development at its upper age bracket of 7.0-7.11 years. In addition, Larson and Summers administered the tests to 216 children from lower socioeconomic backgrounds in Texas and did not find significant differences in the means obtained for subjects in the age groups 5.6 and 6.6 years of age. These results have presented some question regarding the developmental accuracy of the NSST.

\section{Lack of Relationship Between the NSST Scores and}

Spontaneous speech. Are the tests results comparable to the results obtained from a spontaneous speech sample? Prutting et al. (1975) attempted to answer this question by administering the expressive section of the NSST to twelve languagedelayed children 4.1-5.11 years of age. In addition, spontaneous language samples were obtained by a speech-language pathologist and the child's mother. The results revealed that 30 per cent of the syntactyic structures erroneously produced on the NSST were correctly spoken in the spontaneous language samples. These results indicate the NSST scores do not represent an accurate picture of the child's specific expressive language usage. Prutting et al. (1975) recommend the NSST should be used as a "screening instrument to differentiate clinical populations."

When Dailey and Boxx (1979) compared the NSST, the Carrow Elicited Language Inventory (Carrow, 1974), the Menyuk Sentences (Menyuk, 1963) and a spontaneous language sample, they found the NSST results gave the least amount of informa- 
tion regarding the child's overall use of grammar and morphemes. They summarized that the NSST was only a screening tool.

Lack of Reliability and Validity Data. A major criticism of the NSST is the lack of statistical support for its reliability and validity (Arndt, 1977; Byrne, 1977; Fontana, 1978; McCauley and Swisher, 1984; and Wiig and Semel, 1980). No reliability data were presented in the test manual. No test-retest information was available in this author's review of the literature.

Discrimination power and internal consistency were examined in a study by Ratusnik and Koenigsknecht (1975). They tested twenty preschoolers with normal language development, twenty preschoolers who were diagnosed as language impaired and twenty mentally retarded children. The overall expressive scores discriminated the two languageimpaired groups from the group with normal language development. There was no distinction between the overall expressive scores of the two language-deficient groups. The overall scores on the receptive portion of the NSST discriminated between the group with normal 1 anguage development and the language-delayed group. In addition, there was a difference between the mentally retarded preschoolers and the language-delayed children. Through their item analysis of the responses of these groups, they were able to identify the discriminative items and those which did not differentiate 
between the abilities of the children.

As support of the validity of the NSST, Prutting et al. (1975) found that the twelve language-delayed children in their study fell below the loth percentile on the NSST norms. It has been found that children enrolled in speech and language development programs fall below the loth percentile on one or both portions of the NSST. According to Lee (1977), rather than missing children with language deficiencies, the NSST tends to identify children with normal language skills as language impaired rather than identifying a language-delayed child as normal.

Only one report of item analysis (Ratusnik and Koenigsknecht, 1975) was available. In their study they found thirty-nine of forty expressive items differentiated between the language-impaired children and the children with normal language. Only nine of the forty receptive items were found to differentiate between the language-impaired children and the children with normal language.

Lee (1977) has fully acknowledged the lack of statistical analysis of the NSST. Her response has stated that this "instrument was designed to be a diagnostic indicator' or 'an initial screening instrument.'" When it was developed, she did not recommend that an extensive statistical workup be done, because she did not consider it to be a "test" (Lee, 1984). The normative data gathered were useful to their clinic needs (Lee, 1977). In this author's opinion, this explanation seems justified. If a child's 
word order or word form seems questionable, further assessment is recommended.

\section{Summary}

From reviewing the literature available on the NSST, this author has found the NSST is still being used by speechlanguage pathologists. It has been found to have drawbacks, but it has not been discarded. According to Darley (1979) it is: 1) quick and easy to administer and score, 2) involves forms of both receptive and expressive processes, 3 ) covers a restricted range of linguistic structures, and 4 ) tends to over-identify children suspected of a language disorder. It is this author's opinion that the NSST is a useful screening instrument which may be supplemented with a spontaneous language sample. If the child's syntax appears to be deficient, then further in-depth assessment should follow.

According to Longhurst and Schrandt (1973) and McCauley and Swisher (1984), speech-language pathologists need more complete and accurate normative data to enable them to know when a child deviates from the norm significantly enough to warrant intervention. Musselwhite (1983) has emphasized the continued need for normative data on populations other than middle socioeconomic level white children. Until more accurate normative data and improved tests are available, speech-language pathologists should be aware of psychometric criteria and the limitations of the tests they use. They can then make adjustments in their objective and subjective 
decisions regarding the child's language deficiencies or abilities. Lee (1977) specifically recommended normative data be gathered by those who use the NSST in other geographic areas. With these recommendations in mind, this study of the NSST was begun. 
CHAPTER III

METHODS AND PROCEDURES

\section{Subjects}

Forty-four subjects were selected from seven preschools in the Portland, Oregon, Metropolitan area. Twenty-two children were chosen from each of two age groups: 4.0-4.5 and 4.6-4.11 years. Each subject met the following criteria:

1) When administered a pure tone audiometric screening test, the subject responded positively to sound presentations at $25 \mathrm{~dB} H L$ for the frequencies of $500,1000,4000$ and $6000 \mathrm{~Hz}$, unilaterally.

2) The subject was attending preschool classes and was judged by her/his teacher to have no apparent handicapping condition to hinder normal language development.

3) The subject had not received nor was currently receiving speech or language intervention as reported by the parents. (Permission Form appears in Appendix A).

4) The subject spoke standard English as reported by the teacher.

5) The Permission Form (Appendix A) was signed by the 
parent or guardian to allow the subject to participate in the study.

6) The subject was from a middle socioeconomic level home as represented by education and occupation status (U. S. Department of Commerce, 1960) from parent information obtained from the Permission Form (Appendix A).

\section{Instrumentation}

The Northwestern Syntax Screening Test (NSST) devised by Lee $(1969,1971)$ is a screening tool used to test a child's syntactic abilities through specific receptive and expressive tasks. It consists of twenty receptive sentence pairs and twenty expressive sentence pairs which progress from easy to more difficult items (Appendix B).

The examiner administered the entire untimed test (eighty sentences) to each subject following the instructions in the test manual. The testing required approximately twenty minutes per subject.

For this study, each subject's responses on the expressive portion of the NSST were tape recorded using a General Electric cassette tape recorder, Model 3-5314B. The audiometric screening was administered using a portable Beltone 1OD audiometer ANSI 1969.

Test Administration

Each child was brought into a quiet and well-lighted 
testing room in the preschool or school by the examiner. As the examiner brought the subject from the classroom, rapport was established in casual conversation. Upon entering the room, the subject was seated in a chair with his/her back to the audiometer and was given an audiometric screening evaluation.

Upon passing the audiometric puretone screening, the subject was seated in a chair at a table next to the examiner. The Record Score Form and the tape recorder were placed to the examiner's right and the test plates were placed in a pile in front of the child with the appropriate demonstration page on top. To eliminate the possibility of any learning or adaptation effect increasing the scores, the examiner alternated the presentations of the two portions of the NSST as recommended by Lee (1977). Eleven of the subjects in each analysis age group were presented the expressive items before the receptive items.

The examiner followed the manual instructions in administering the NSST, being careful not to overemphasize key words or use exaggerated intonation patterns when presenting the stimulus sentences. Upon completion of administration of the entire NSST, the subject was reinforced for his cooperation and performance by verbal praise and a sticker. The entire screening, including the audiometric puretone screening, and testing were done in approximately one twenty-five minute session per subject. 


\section{Scoring Procedures}

The subject's responses were recorded by the examiner on the NSST Record Form (Appendix B). The manual instruction guidelines for scoring the test were followed. One point was given for each correct response with a possible two points for each sentence pair. If all items received correct responses, a score of forty points for the receptive items and forty points for the expressive items leighty total points) was awarded.

\section{Data Analysis}

The data were computed and a total score was obtained for the receptive and expressive sections of the NSST for each child. Descriptive statistics were then applied to determine the means, standard deviations and percentiles for each age group.

In order to perform a comparison analysis of the statistical information obtained from this study and the data obtained by Lee $(1969,1971)$, the pooled sum of squares was computed and standard deviations were found. Two-tailed t-tests for independent means were applied to these scores to determine the significance of the differences between the two groups. 
CHAPTER IV

\section{RESULTS AND DISCUSSION}

\section{$\underline{\text { Results }}$}

The purpose of this study was to compare NSST data (Lee, 1969; 1971) with data obtained in Portland, Oregon for children 4.0-4.11 years of age. Preliminary to answering the questions of this study, t-tests were computed to analyze the ordering effect of the presentations of the two subtests. In order to control for an order effect, the receptive and expressive sections of the NSST were alternately presented first. Eleven subjects in the 4.0-4.5 age group were given the expressive section first and the other eleven subjects were given the receptive section first. The same procedure was followed for the twenty-two subjects in the 4.6-4.11 year age group. The subjects' test results were treated as one age group, 4.0-4.11 years, but were divided into groups according to which section they had received first. Then means and standard deviations were computed and a $\underline{t}$-test applied. The results showed $\underline{t}=.91$ on the receptive section when comparing the subjects who received the receptive section first with those who received the expression section first. A $\underline{t}$-score of .82 was found on the expressive section when the same two groups were 
compared. These results indicate statistically insignificant differences between the scores of subjects who were administered the receptive portion first and those who received the expressive portion first.

The first research question posed by this study was: Is there a significant difference between the expressive and receptive NSST scores obtained by Lee $(1969,1971)$ and the scores in Portland, Oregon? To answer this question, the means and standard deviations were determined and compared with the Lee $(1969,1971)$ data to determine if there was a statistical significance between the data of the two studies. The results of the analysis are shown in Table I. The mean $(\bar{x})$ score on the receptive portion of the NSST was 27.95 with a standard deviation of 4.28 . The mean score of the Lee $(1969,1971)$ study was 27 with a standard deviation of 4.73 . When a two-tailed t-test was applied, the results showed $\underline{t}=.21$, indicating no statistically significant difference between the means of the two groups of children studied.

On the expressive portion of the NSST, the mean score of the children in this study was 24.42 with a standard deviation of 5.69. This was compared to the mean score of 25 and standard deviation of 5.39 in the Lee $(1969,1971)$ study, which resulted in a $\underline{t}$ of .11 indicating no statistically significant difference in scores between the two groups studied. 
The second question posed was: What are the means, standard deviations and percentiles of the NSST scores of a select group of four-year-old children in Portland, Oregon? The data from this study revealed the mean score of 27.95 and a standard deviation of 4.28 on the receptive portion of the NSST. On the expressive portion, the subjects' scores revealed a mean score of 24.43 and a standard deviation of 5.69 .

Table II shows the percentiles of the Portland subjects on the receptive portion of the NSST. The 10th, 25th, 50th, 75 th and 90 th percentile values represent the number of correct items and are 22, 25, 28, 32 and 33, respectively. On the expressive portion of the NSST, this study finds the percentiles of $17,21,24,31$ and 32 for the 10th, 25th, 50 th, 75th and 90th percentiles, respectively. The information to answer the second question this study sought to answer can be found in Tables I and II.

\section{Discussion}

The purpose of this study was to compare the NSST normative data (Lee, 1969, 1971) with data obtained in Portland, Oregon for children 4.0-4.11 years of age. The results obtained from this study revealed no significant differences from the results obtained from children in the Lee study. These results thus indicate that four-year-old children in these two geographical areas have similar responses to the NSST. These results support the use of 
TABLE I

COMPARISON OF NSST MEANS AND STANDARD DEVIATIONS

OBTAINED IN THE MIDWEST AND PORTLAND, OREGON

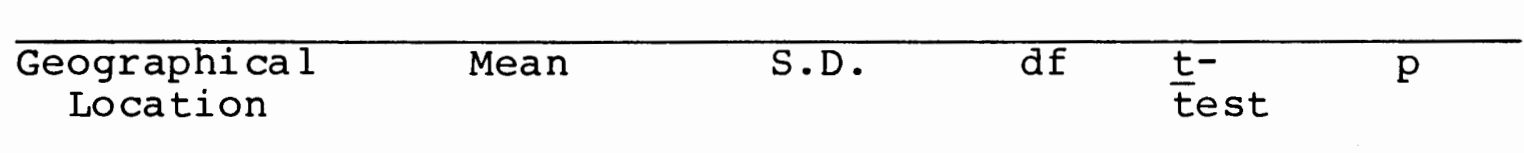

Receptive Section:

Midwest

(1969, 1971)

Portland

27

(1984)
$27.95 \quad 4.28$

104

.21

$>.05$

4.73

5.39

$104 \quad .11>.05$

Expressive Section:

Midwest 25

(1969, 1971)

Portland

24.43

5.69

the Lee norms for Portland, Oregon children in this age group. It had been hypothesized that the NSST norms were too high for many geographical and middle-income areas other than the Northwestern University area where the original study was conducted (Arndt, 1977; Fontana,1978; Larson and Summers,

1976). It must be noted that this may be true for the threefive- and six-year olds since normative data on these age groups in this region are not available.

The subjects chosen for this study attended various preschools throughout the Portland Metropolitan area. Two preschools were located in Portland and five others were in surrounding suburbs (Gladstone, Milwaukie, Beaverton, Lake Oswego and Tigard). The preschools had varied structures; some were day care centers and others had more structured 
TABLE II

COMPARISON OF NUMBER OF CORRECT ITEMS PER SUBJECT

IN EACH PERCENTILE RANK USING MIDWEST NORMS AND

PORTLAND, OREGON NORMS

Receptive

section:

Percentile

Moore

Lee

Above/bel ow Lee

study

study

Scores

\section{Expressive}

\section{section:}

Percentile

Moore

Lee

Above/Below Lee

study

study

Scores

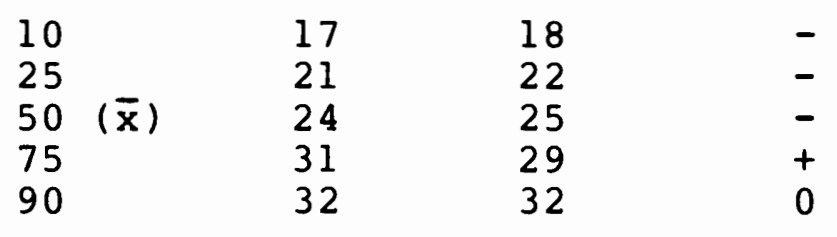

educational programs. Preschool structure was a consideration in this study, because in a more structured setting, more listening and formal language activities would probably be included. The unstructured day care programs would provide for informal social interactions. Information regarding the preschool structure of Lee subjects was not available.

The children chosen for this study were from families within the middle-income level. The criterion which was used 
for subject selection ensured that children from upper-income level families were not included in this study. A criticism of the NSST norms has been that the children used for the published normative data were from families with higher income levels (Arndt, 1977; Fontana, 1978; Larson and Summers, 1976). Critics indicated that this was a factor in the establishment of norms which seemed generally higher than one would find in children from middle-income families. Children from higher income level families may have been exposed to a broader vocabulary and language model than those from lower socioeconomic level homes. This study does not support this critique for the four-year-old age group in this region.

The percentile rankings of the two groups were studied because subjects with scores below the loth percentile and/or two standard deviations below the mean are recommended for further language evaluation. In other words, children with scores two standard deviations below the mean are considered probable candidates for further testing and evaluation. In comparing the results of Lee's study $(1969,1971)$ with the results from this study, it was found that the loth percentile score on the receptive section of the NSST was slightly higher for this study (22) than the Lee loth percentile score of 21 . One point is not a clinically significant difference, but the examiner may want to be aware of this difference.

The 10th percentile score of 17 on the expressive 
section of the NSST for this study was lower than the loth percentile score of 18 in the Lee study. The clinical result would be over-identification of a small percentage of children rather than missing any language-impaired children. As a clinician, it is this researcher's preference to overidentify rather than not to identify children with possible language problems.

The results of this study show that the four-year old children generally receive higher scores with increased age. Figures 1 and 2 display a scattergram of NSST scores in relation to the age of the subjects. In studying Figures 1 , 2 and Table I further, it is evident that the children scored higher on the receptive section than they did on the expressive section. These results support the normal language development findings of Fraser et al. (1963) who found that for most children the receptive processing of language develops before the expressive production of language.

Using the information obtained in this study, this researcher examined the number of errors per item on the NSST to determine which items were frequently missed.

This information is presented in Table III. The items on the receptive section most frequently missed by the subjects $4.0-$ 4.5 years of age were the following sentences sequenced by frequency of errors:

20. a) The mother shows the kitty the baby.

b) This is my hat. (818)

17. a) Has Daddy finished dinner? (778)

20. b) The mother shows the baby the kitty.

14.

b) Is the dog in the box?

( 728$)$ 
FIGURE 1. Scattergram of Score Distribution on Receptive Section of the NSST

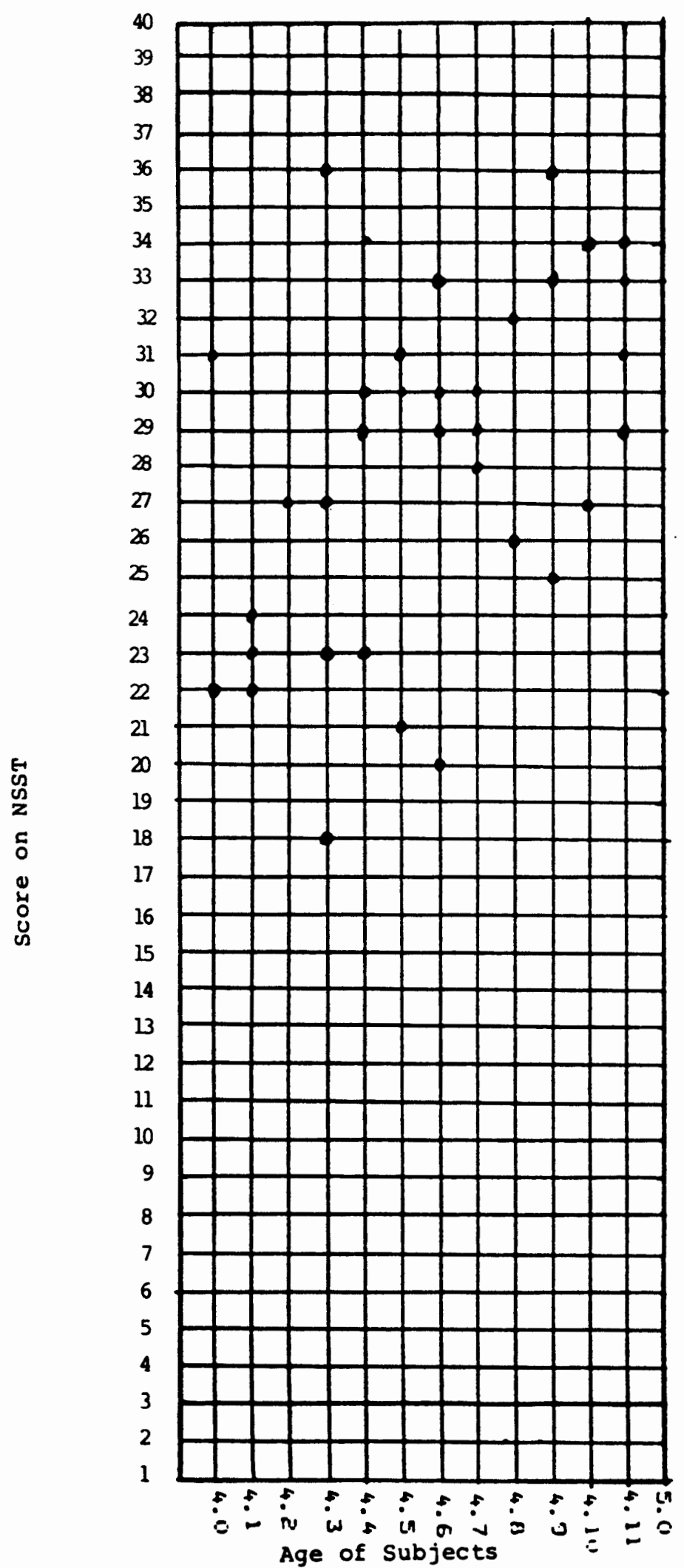


FIGURE 2. Scattergram of Score Distribution on Expressive Section of the NSST

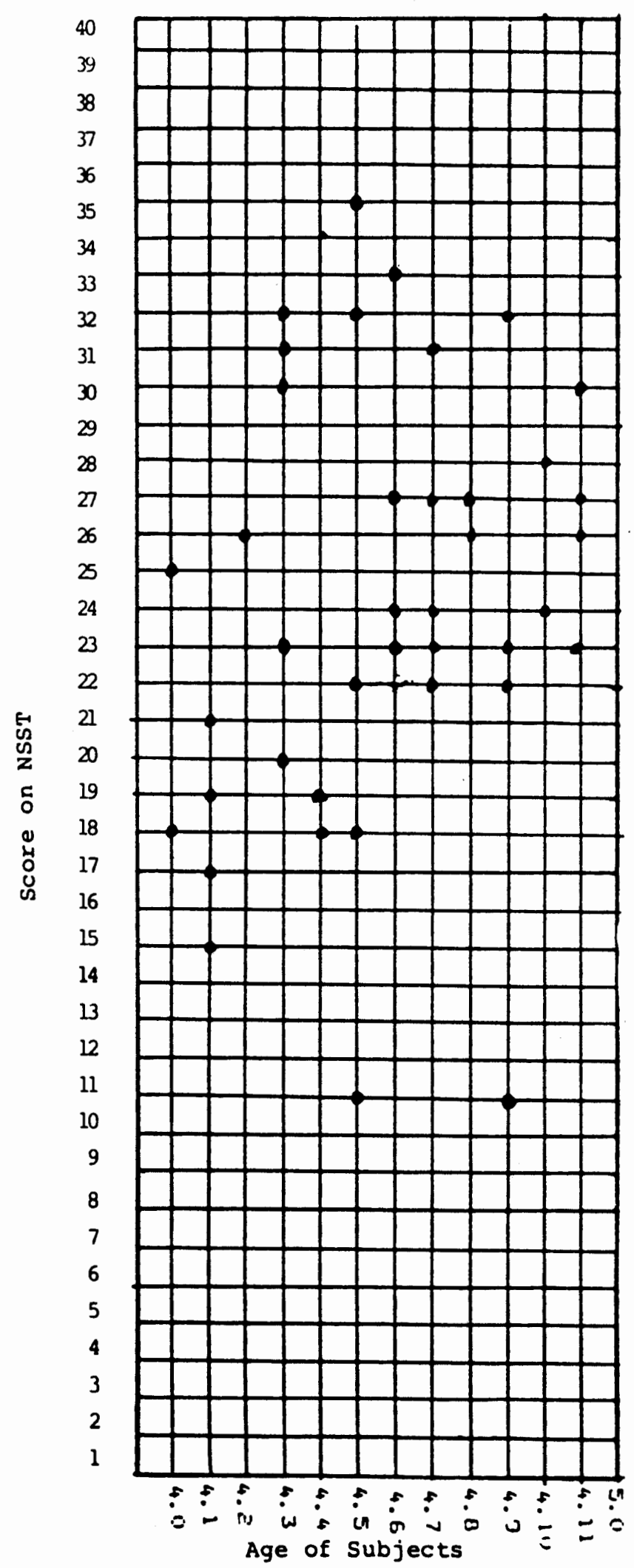


19. a) That is my hat. (598)

The subjects in the 4.6-4.11 year age group most frequently errored on the following sentences:

17. a) Has Daddy $f$ inished dinner? ( 868 )

20. a) The mother shows the kitty the baby. (688)

14. b) Is the dog in the box? (688)

20. b) The mother shows the baby the kitty. (548)

These items contain more complex and later-developing

language concepts such as longer word string, interrogative sentences and demonstrative pronouns.

The most frequent errors on the expressive section by the subjects in the 4.0-4.5 year age group were the following sentences arranged in order of frequency of errors:

20. b) The man brings the girl the boy.

a) The man brings the boy the girl.

17. a) Has the boy found his ball? (868)

13. b) Is the car in the garage? ( 868 )

18. a) This is a baby doll. (868)

11. a) The boy washes himself. (818)

Subjects in the 4.6-4.11 year age group most frequently missed the following items:
20.
a) The man brings the girl the boy. (100\%)
b) The man brings the boy the girl. (86\%)
18. a) This is a baby doll. (728)
17. a) Has the boy found his ball?
15. a) The boy jumped. (728)

The most frequent responses to the sentences were:

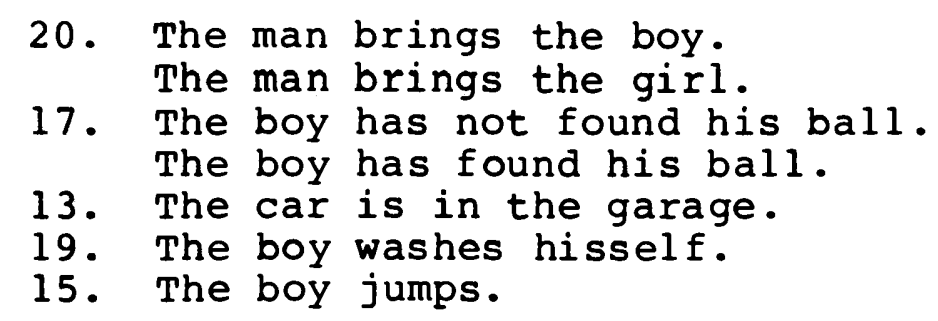

These responses reveal a tendency for the subjects to: 1) answer the interrogative sentences rather than repeating 
TABLE III

ITEM ANALYSIS

FREQUENCY OF ERRORS PER TEST ITEM

RECEPTIVE

EXPRESSIVE

\begin{tabular}{|c|c|c|c|}
\hline $\begin{array}{l}\text { Age: } \\
4.0-4.5\end{array}$ & $4.6-4.11$ & $4.0-4.5$ & $4.6-4.11$ \\
\hline
\end{tabular}

Item:

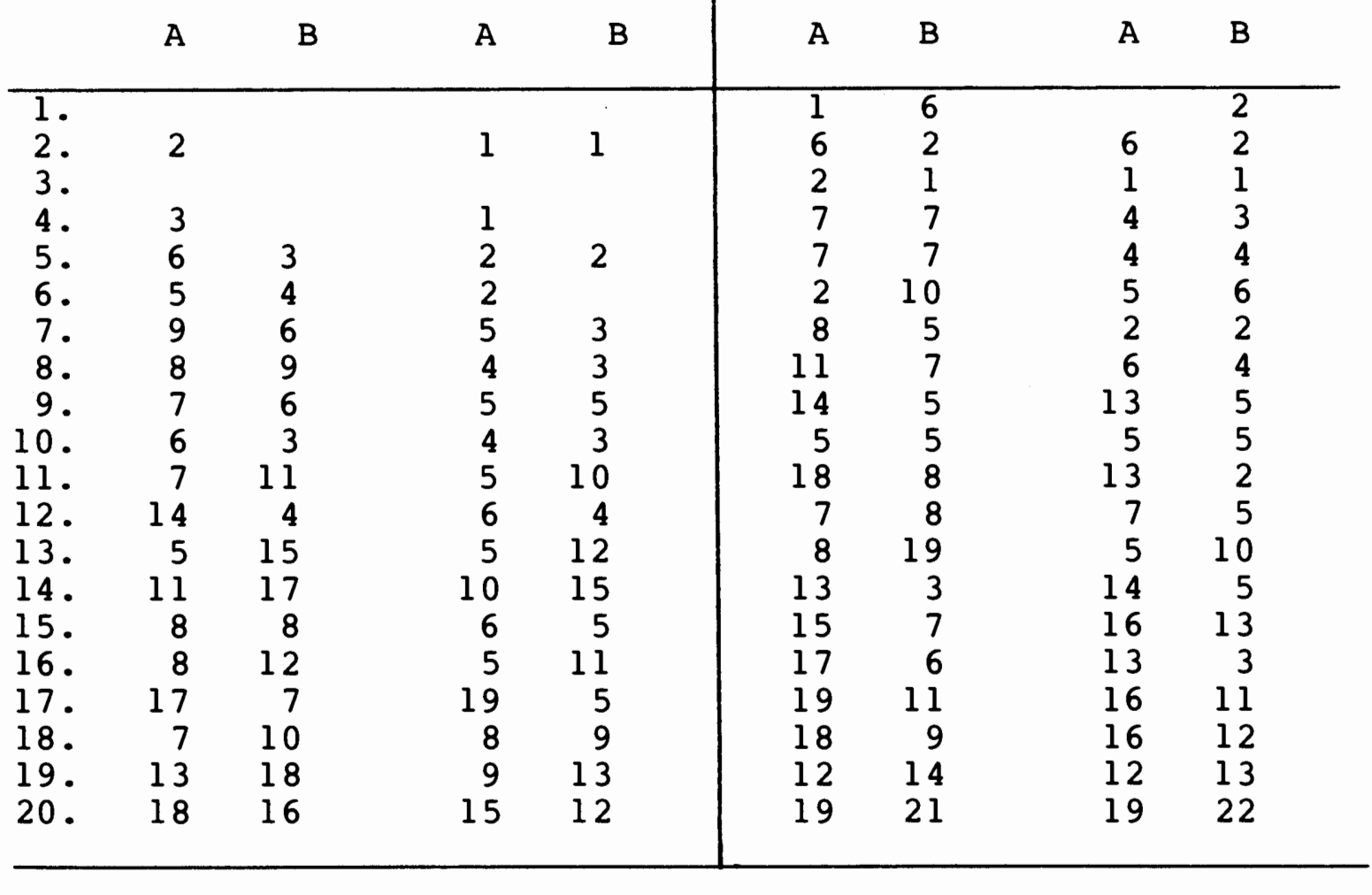


them; 2) shorten a long word string; and 3) repeat the same response for both pictures.

In summary, this study obtained data on the performance of four-year-old children from the Portland, Oregon area on the NSST and compared these data to the norms obtained by Lee (1969, 1971). The results indicate that the responses obtained were similar for both geographical groups. This information lends support for the use of the NSST norms for this age group. Higher scores were recorded on the receptive section of the NSST than on the expressive section which coincides with earlier normal language development studies (Fraser et al. 1963). From an analysis of the frequency of errors per item, it was found that several items were found to be weak. 


\author{
CHAPTER V \\ SUMMARY AND IMPLICATIONS
}

\title{
Summary
}

Numerous tests have been developed to assess the language abilities of children. In an attempt to develop an efficient tool for screening the morphological and syntactical language skills of children, Lee $(1969,1971)$ and her students produced the Northwestern Syntax Screening Test (NSST).

The purpose of this study was to compare NSST data (Lee, 1969, 1971) with data obtained in Portland, Oregon for children 4.0-4.11 years of age. The questions this study sought to answer were: 1) Is there a significant difference between the expressive and receptive scores obtained by Lee, (1969, 1971) and the scores obtained in Portland, Oregon? 2 ) What are the means, standard deviations and percentiles of the NSST scores of a select group of four-year-old children in Portland, Oregon?

Twenty-two children, 4.0-4.5 years of age, and twentytwo children, 4.6-4.11 years of age, were selected as subjects. They met the following criteria: normal hearing, no apparent speech or language deficiencies (past or present), speaks standard English, from middle socioeconomic level home 
and parent permission received.

The mean score on the receptive portion of the NSST for the children tested in this study was 27.95 with a standard deviation of 4.28. The Lee $(1969,1971)$ data revealed a mean score of 27 with a standard deviation of 5.69 . The Lee (1969, 1971) study resulted in an expressive mean score of 25 with a standard deviation of 5.39. When a two-tailed t-test was used, the results showed no statistically significant difference between the data of the two studies.

This study revealed information to support: 1) the use of the NSST norms for the Portland, Oregon four-year-old group; and 2) findings that the receptive language processing skills develop before the expressive language skills. In addition, the frequency of errors on certain items revealed item weakness.

\section{Implications}

\section{$\underline{\text { Research Implications }}$}

This reviewer finds the NSST to have methodological weaknesses which have also been described in chapter II. Lack of standardization of testing methods, little data to support the reliability and validity of the test, and weakness in the test items are three major flaws. If further research is done with the NSST, these areas should be investigated.

Results indicate that several items received a large 
number of errors suggesting weaknesses. The items that were difficult for most subjects should be studied and probably revised. A revision of the pictures and the stimulus sentences should be done so that the same aspects of language are being evaluated. It is suggested that a reordering of the test items be done to allow the items to progress from the easier to the more difficult. The item analysis of this study indicates this progression is not present.

If a similar study is pursued, a larger number of subjects from other localities is recommended to ensure a representative sampling of the of the population. This study included forty-four subjects from various sections of the city in order to sample subjects from various socioeconomic backgrounds.

A shortened version of the NSST has been developed (Ratusnik, Klee, and Ratusnik, 1980); however, this version needs further research. If the results of this shortened version identify language deficient children with similar results as the NSST, it would seem feasible to use this less time-consuming version of screening assessment. This researcher would recommend further investigation of this tool.

This study revealed norms similar to the Lee norms for the four-year-old age group in Portland, Oregon. It is recommended that similar research be done on the other age groups to ensure that the Lee norms are comparable to those found in this region.

If further research is done on the NSST, the alternate 
presentation of the receptive and expressive sections should be kept in mind to avoid the effect of learning the task to influence the results. This recommendation was made by Lee (1977) and is an important consideration.

\section{Clinical Implications}

The NSST has been a tool used by many speech-language pathologists. The results of this study support the Lee (1969, 1971) normative data for the four-year old age group in this geographical area.

It is this author's opinion that anyone who uses the NSST should be aware of it's weaknesses. The lack of standardization methods places the usefulness of the cut-off scores, the loth percentile and/or two standard deviations, in question. It is the opinion of this researcher, that in the hands of an experienced clinician, this tool can be helpful in locating children who may have language deficiencies.

The results of this study support the correlation of increased language development with increased age. With increased age, the means of the NSST scores increased. In order to assess the child's language effectively, these results emphasize the importance of the examiner's knowledge of the subject's age in years and months.

Knowledge of the specific language concept being assessed by the test is recommended. The examiner can note 
which items are developmentally expected for the particular age level. A reordering of some of the test items would be helpful in meeting this qualification.

The expressive portion of the NSST serves as a sampling of the child's speech skills. Throughout this section the examiner may note the child's articulation skills in sentences.

It is this author's opinion that following the employment of the NSST as a screening instrument by an experienced examiner who is familiar with the test, if the child's language skills are identified as being low, the use of indepth assessment measures, spontaneous speech sampling and consideration of the child's intellectual and social levels will enable the speech-language pathologist to determine whether language intervention is needed. 


\section{BIBLIOGRAPHY}

ARNDT, W. (1977). A psychometric evaluation of the Northwestern Syntax Screening Test. Journal of Speech and Hearing Disorders, 42, 316-319.

BANNATYNE, M. (1975). Review of the Northwestern Syntax Screening Test, Journal of Learning Disorders, 8, 196197 .

BERKO, J. (1958). Berko Test of Morphology. Word, 14, 150-177.

BROWN, R. (1973). A first language: The early stages. Cambridge, Mass: Harvard University Press.

BRYNE, M. (1977). A clinician looks at the Northwestern Syntax Screening Test. Journal of Speech and Hearing Disorders, 42, 320-321.

CALLAHAN, M. (1974). An investigation of the influence of dialectal interferences on the NSST scores obtained by Portland Black children. Masters thesis, Portland State University.

CARROW, E. (1974). Carrow El icited Language Inventory. Austin, Texas: Learning Concepts.

CARROW, SR. M. (1968a). The development of auditory comprehension of language structures in children. Journal of Speech and Hearing Disorders, 33, 99-111.

CARROW, SR. M. (1968b). Test of Auditory Comprehension of Language. Austin, Texas: Urban Research Group.

CHOMSKY, N. (1965) Aspects of the theory of syntax. Cambridge, Mass: MIT Press.

DAILEY, K., And BOXX, J. (1979). A comparison of three imitative tests of expressive language and spontaneous language sample. Language Speech and Hearing Services in the Schools, 6-13.

DARLEY, F. (Ed.) (1979). Evaluation of appraisal techniques in speech and language pathology. Reading, MA: Addison-Wesley. 
DAVIS, J., and HARDICK, E. (1981). Rehabilitative audiology for children and adults. New York: John Wiley and Sons, Inc.

FONTANA, M. (1978). Northestern Syntax Screening Test. In 0 . Buros (Ed.), Eighth mental measurements yearbook. Highland Park, NJ: Gryphon Press.

FRASER, C., BELLUGI, U., and BROWN, R., (1963). Control of grammar in imitation, comprehension, and production. Journal of Verbal Learning and Verbal Behavior, 2, $121-135$.

KIRK, S., MCCARTHY, J., and KIRK, W. (1968). The Illinois Test of Psycholingustic Abilities. (rev. ed.) Urbana: University of Illinois Press.

LARSON, G., and SUMMERS, P. (1976). Response patterns of pre-school age children to the Northwestern Syntax Screening Test. Journal of Speech and Hearing Disorders, $41,486-497$.

LEE, L. (1969, 1971). Northwestern Syntax Screening Test. Evanston, Ill: Nor thwestern University Press.

LEE, L. (1970). A screening test for syntax development. Journal of Speech and Hearing Disorders, 35, 103-112.

LEE, L. (1977). Reply to Arndt and Bryne. Journal of Speech and Hearing Disorders, 42, 323-327.

LEE, L. (1984). Correspondence through a personal letter. Evanston, Ill.

LEREA, L. (1958a). Assessing language development. Journal of Speech and Hearing Research, 1, 75-85.

LEREÁ, L. (1958b). The Michigan Picture Language Inventory. Ann Arbor: Uni versity of Michigan.

LOGUE, R. (1978). Northwestern Syntax Screening Test. In o. Buros (Ed.) Eighth mental measurements yearbook. Highland Park, NJ: Gryphon Press.

LONGHURST, T. and SCHRANDT, T. (1973). Linguistic analysis of children's speech: a comparison of four procedures. Journal of Speech and Hearing Disorders, 28, 240-249.

MARTIN J. and ENGEL, (1978). A comparison of two procedures (NSST and concrete objects) for measuring receptive and expressive language of mentally retarded children. Language, Speech and Hearing Services in the Schools, 9, 176-182. 
MCCAULEY, R., and SWISHER, L. (1984). Psychometric review of language and articulation tests for preschool children. Journal of Speech and Hearing Disorders, 49, 34-4l.

MENYUK, P. (1963). Preliminary evaluation of grammatical capacity in children. Journal of Verbal Learning and Verbal Behavior, 2, 429-439.

MOLINA, H. (L976). Screening Test of Spanish Grammar. In O. Buros (Ed.) Eighth mental measurements yearbook. Highland Park, NJ: Gryphone Press.

MUSSELWHITE, C. (1983). Pluralistic assessment in speechlanaguage pathology: Use of dual norms in the placement process. Language Speech and Hearing Services in the Schools, $1 \overline{4,29-37}$.

NATALICIO, D. (1976). Screening Test of Spanish Grammar. In O. Buros (Ed.) Eighth mental measurements yearbook. Highland Park, NJ: Gryphone Press.

NATION, J. and ARAM, D. (1977). Diagnosis of speech and language disorders. St. Louis: C.V. Mosby Company.

PETERSON, H. and MARQUARDT, T. (1981). Appraisal and diagnosis of speech and language disorders. Englewood Cliffs, New Jersey: Prentice-Hall, Inc.

PRESSNELL, L. (1973). Hearing-impaired children's comprehension. and production of syntax in oral language. Journal of Speech and Hearing Research, $16,12-21$.

PRUTT ING, C., GALLAGHER, T., and MULAC, A. (1975). The expressive portion of the NSST compared to a spontaneous language sample. Journal of Speech and Hearing Disorders, $40,40-48$.

RATUSNIK, D., KLEE, T. and RATUSNIK, C. (1980). Northwestern syntax screening test: A short form. Journal of Speech and Hearing Disorders, 45, 200-208.

RATUSNIK, D., and KOENIGSKNECHT, R. (1975). Internal consistency of the Northwestern Syntax screening Test. Journal of Speech and Hearing Disorders, 40, 59-68.

TORONTO, A. (1973). A Screening Test of Spanish Grammar. Evanston, Ill: Northwestern University Press.

UNITED STATES DEPARTMENT OF COMMERCE. Methodology in scores of socioeconomic status, 1960 .

WIIG, E., and SEMEL, E. (1980). Language Assessment and 
Intervention for the Learning Disabled. Columbus: Charles E. Merrill Publishing Co.

WOLFRAM, W. (1972). Handout at ASHA convention presentation.

WOOD, B. (1981). Children and communication: Verbal and nonverbal language development. Englewood Cliffs, New Jersey: Prentice-Hall, Inc. 


\section{APPENDIX A}

\section{PERMISSION FORM}

I agree to let my child, participate as a subject in the study entitled "A Comparative study of the Northwestern Syntax Screening Test Data." This study will be conducted by Sharon Moore under the supervision of Mary Gordon, thesis director, Speech and Hearing Sciences, Portland State University.

In this study my child will be given a brief hearing screening and the Northwestern syntax Screening Test which involves pointing to pictures described by the examiner and repeating some sentences. There are no risks or dangers involved in this study. I am free to withdraw my child from this study at any time. No names will be used in the written results. The testing session will require about twenty-five minutes.

The purpose of this study is to compare the language used by children in Portland, Oregon, with the language used by children in Illinois.

Signature of Parent

Date

\section{Birthdate of my child}

The following information will be helpful:

OCCUPATION OF THE PRIMARY WAGE EARNER

YEARS OF EDUCATION OF THE PRIMARY WAGE EARNER (Circle one) 12 $\begin{array}{llllllllllllllllll}3 & 4 & 5 & 6 & 7 & 8 & 9 & 10 & 11 & 12 & 13 & 14 & 15 & 16 & 17 & 18 & 19\end{array}$

MY CHILD HAS/HAS NOT BEEN IN SPEECH OR LANGUAGE THERAPY

Please complete and return this form to your child's teacher tomorrow. If you have any questions, please feel free to call me at 635-2988. Thank you for your cooperation. 
NORTHWESTERN SYNTAX SCREENING TEST

RECORD FORM

Name Sex

Date B.D.

Receptive Score Expressive Score C.A.

Examiner Testing Location

RECEPT IVE ITEMS :

1. The cat is behind the chair. The cat is under the chair.*

2. She goes upstairs.* He goes upstairs.

3. The cat is on the cupboard. The cat is in the cupboard.*

4. The boy is sitting.* The boy is not sitting.

5. The deer is running.* The deer are running.

6. The boy sees the cat. The boy sees the cats. *

7. The boy sees himself. The boy sees the shelf.*

8. The milk spilled. The milk spills. *

9. The car hits the train. The train hits the car.*

10. This is their dog.* This is her dog.

11. This is a mother cat. * This is Mother's cat.

12. The girl will drink.* The girl is drinking.

13. Mother says, "Look who is here." Mother says, "Look what is here." *

14. The $\operatorname{dog}$ is in the box. Is the dog in the box? *

15. The boy writes. The boys write.*

16. Mother says, "Where is that girl?"* Mother says, "Who is that girl?"

17. Has Daddy finished dinner? Daddy has finished dinner.*

18. The boy is pushed by the girl.* The girl is pushed by the boy.

19. This is my hat.* That is my hat.

20. The mother shows the kitty the baby.* The mother shows the baby the kitty. 
EXPRESSIVE ITEMS:

1. The baby is sleeping. *

The baby is not sleeping.

2. The $\operatorname{dog}$ is on the box.

The $\operatorname{dog}$ is in the box. *

3. She sees the car. *

He sees the car.

4. The cat is behind the desk.

The cat is under the desk.*

5. The boy pulls the girl.

The girl pulls the boy.*

6. The fish is swimming. *

The fish are swimming.

7. The girl sees the dog.

The girl sees the dogs. *

8. This is their wagon. *

This is his wagon.

9. The cats play.

The cat plays. *

10. Mother says, "Where is that boy?"*

Mother says, "Who is that boy?"

11. The boy washes himself.

The boy washes the shelf.*

12. This is my dog.*

That is my dog.

13. The car is in the garage. 
Is the car in the garage?*

14. The boy will throw.* The boy is throwing.

15. The boy jumped. The boy jumps * *

16. Mother says, "Look who I found." Mother says, "Look what I found."*

17. Has the boy found his ball? The boy has found his ball.*

18. This is a baby doll. * This is Baby's doll.

19. The boy is pulled by the girl. * The girl is pulled by the boy. 20. The man brings the girl the boy.* The man brings the boy the girl. 